\title{
Study on Relationship between Tobacco Canopy Spectra and LAI
}

\author{
Hongbo Qiao ${ }^{1}$, Weng Mei ${ }^{1}$, Yafei Yang ${ }^{1}$, Wang Yong ${ }^{2}$, Jishuai Zhang ${ }^{2}$, \\ and $\mathrm{Yu} \mathrm{Hua}{ }^{1, *}$ \\ ${ }^{1}$ College of information and management science, Henan agricultural university, P. R. China \\ ${ }^{2}$ Sanmenxia Branch of Henan Tobacco Company, Sanmenxia, P. R. China \\ qiaohb@126. com
}

\begin{abstract}
N nutrition is one of the most important limitation factors for crop growth and yield. Precise and timely monitoring and detection of crop $\mathrm{N}$ nutrient conditions is necessary for improving the efficiency of $\mathrm{N}$ nutrition using and crop management, reducing environmental pollution caused by over nitrogen fertilizer application. In this paper the canopy reflectance spectra during the whole growth period on tobacco field plots treated with different nitrogen levels were periodically and continually measured. LAI of tobacco of several important growth periods was meanwhile measured. The results showed that tobacco canopy spectral reflectance of different growing periods changed regularly with the increase of nitrogen fertilizer application. The canopy spectral reflectance increased in $710 \sim 1000 \mathrm{~nm}$, while decreased in $460 \sim 680 \mathrm{~nm}$. There was high correlations between NDVI and LAI. The research supply theoretical foundation for tobacco $\mathrm{N}$ management.
\end{abstract}

Keywords: Tobacco; spectra; LAI.

\section{Introduction}

Crop canopy spectrometry is a harmless remote determination technique. It is a current effective remote monitoring method of crop growth state. The reflectance spectral curve of plant has significant characteristics. For same plant, spectral curve varies with fertility levels and development stage ${ }^{[1]}$. Thus, spectral curve characteristics could reflect plant growth state.

Biochemical parameters of plant canopy estimated through remote technique can understand the productivity of plant and the effectiveness of soil nutrients ${ }^{[2,3]}$. Svetlana et.al. ${ }^{[4]}$ determined the chlorophyll content in leaf of wheat, maize, beet and grape, established the first-order differentiation of canopy spectrum and the regression equation model of chlorophyll content, which could estimated the chlorophyll content in different crop species. Daughtry et.al. ${ }^{[5]}$ determined the canopy spectrum of maize at 8 nitrogen fertilizer levels, and the screened MCARI and NIR/Green vegetation index

\footnotetext{
* Corresponding author.
} 
were significantly related to the chlorophyll content in leaf. The chlorophyll content in canopy was very sensitive to nitrogen reserve in soil ${ }^{[3]}$. Thus, chlorophyll content could be used to monitor the abundance and deficiency of nitrogen in soil. Elizabeth et.al. ${ }^{[6]}$ estimated the chlorophyll content in potato through PROSAIL model, which could predict the nitrogen content in soil at late growth stage.

LAI is one of most basic parameters to reflect the structure of vegetation canopy, and is also key determination factor of biomass and yield ${ }^{[7]}$. Wu et.al. ${ }^{[8]}$ established the correlation model of vegetation index with maize/potato LAI based on QuickBird satellite image, and modified soil adjusted vegetation index (MSAVI) was more accurate $\left(\mathrm{R}^{2}=0.63\right.$ and $\left.\mathrm{R}^{2}=0.79\right)$. in the study of Daughtry et.al. ${ }^{[5]}$, in maize at different nitrogen fertilizer levels, the reflectance varied with the increase in LAI and chlorophyll content (at maximum extent near red edge $715 \mathrm{~nm}$ ), and moved toward long wave. Hung et.al. ${ }^{[9]}$ established the partial least square regression model of rice reflectance spectrum with canopy LAI $\left(\mathrm{R}^{2}>0.79\right)$ to better evaluate the growth state of rice mainly within near-infrared, visible light and red edge $707 \mathrm{~nm}$ range.

Above studies verified the estimation of chlorophyll and LAI through remote technique, mainly for wheat and maize, but seldom for tobacco. Tobacco is harvested through leaf, and it is significant to monitor its LAI and chlorophyll content. This study tested tobacco under different fertilization conditions, defined the change law of chlorophyll content/LAI/canopy spectral characteristics, determined the correlation of vegetation index with chlorophyll content and LAI at different waveband combinations, confirmed whether canopy spectrum could be used to estimate LAI and chlorophyll content, and provided technological means for quick harmless large-area obtaining of information on the growth state of tobacco.

\section{Materials and Methods}

\subsection{Experiment Design}

5 levels of nitrogen fertilizer: N0 $\left(0 \mathrm{~kg} / \mathrm{hm}^{2}\right), \mathrm{N} 1\left(22.5 \mathrm{~kg} / \mathrm{hm}^{2}\right), \mathrm{N} 2\left(45 \mathrm{~kg} / \mathrm{hm}^{2}\right), \mathrm{N} 3$ $\left(67.5 \mathrm{~kg} / \mathrm{hm}^{2}\right)$ and $\mathrm{N} 4\left(90 \mathrm{~kg} / \mathrm{hm}^{2}\right) .3$ levels of organics: Low $\left(225 \mathrm{~kg} / \mathrm{hm}^{2}\right)$, middle $\left(375 \mathrm{~kg} / \mathrm{hm}^{2}\right)$ and high $\left(525 \mathrm{~kg} / \mathrm{hm}^{2}\right)$. No base fertilizer, repeat each treatment for 3 times, and randomly divide into 45 blocks $(12 \mathrm{~m} \times 6 \mathrm{~m})$. Qin tobacco \#96, at a row spacing of $1.2 \mathrm{~m}$ and a plant spacing of $0.6 \mathrm{~m}$.

Experiment 1: At National Modern Tobacco Demonstrative Area in Mianchi County, Sanmenxia City, Henan, China (north latitude 34 $37^{\prime} 52.96^{\prime \prime}$ and east longitude $\left.111^{\circ} 44^{\prime} 28.24^{\prime \prime}\right)$. Surface layer $0 \sim 20 \mathrm{~cm}$, soil organics $12.3 \mathrm{~g} / \mathrm{kg}$, total nitrogen $0.74 \mathrm{mg} / \mathrm{kg}$, effective phosphorus $9.7 \mathrm{mg} / \mathrm{kg}$, quick-acting potassium $120 \mathrm{mg} / \mathrm{kg}$, and soil pH8.2.

Experiment 2: At Xuedian Village, Zhuyang Town, Lingbao City, Henan, China (north latitude $34^{\circ} 17^{\prime} 13.56^{\prime \prime}$ and east longitude $\left.110^{\circ} 44^{\prime} 29.04^{\prime \prime}\right)$. Surface layer 0 20cm, soil organics $11.9 \mathrm{~g} / \mathrm{kg}$, total nitrogen $0.8 \mathrm{mg} / \mathrm{kg}$, effective phosphorus $7.2 \mathrm{mg} / \mathrm{kg}$, quick-acting potassium $132 \mathrm{mg} / \mathrm{kg}$, and soil $\mathrm{pH} 7.9$. 


\subsection{Spectral Data Collection}

This study made spectrometry at characteristic growth stage of tobacco: Seedling stage (June 20, 2009), resettling growth stage (July 19, 2009), vigorous growth stage (August 11,2009 ), early-maturity stage (September 5,2009 ) and maturity stage (September 23, 2009). Canopy spectrometer adopted portable hyperspectral radiometer of American ASD Co. (HandHeld), spectral range 325 1050nm, spectral resolution 1.4nm, field angle $25^{\circ}$. Make spectrometry in 3 tobacco plants of same growth state at each treatment, determine canopy spectral reflectance at 10:00 14:00 in sunny windless climate, with sensor probe vertically downwards and at $60 \mathrm{~cm}$ vertically away from canopy top. Calibrate standard white plate before each determination, record data in 20 groups, and regard their mean as spectral reflectance value of this treatment.

\subsection{Determination of Leaf Area and Chlorophyll Content}

$$
\text { LAI=Length } \times \text { width } \times 0.6345^{[10]}
$$

Chlorophyll content: SPAD-502 chlorophyll detector of Japan MINOLTA Co. was used to determine spectrum and chlorophyll content in tobacco, i.e. Specialty Products Agricultural Division (SPAD). According to the absorptivity of leaf chlorophyll to colored light, SPAD-502 chlorophyll detector determined the chlorophyll content in leaf by determining the intensity of emission light at a certain wavelength and that of light through leaf. SPAD-502 chlorophyll detector had 2 emission light sources to emit red light of maximum $650 \mathrm{~nm}$ and infrared light of maximum $940 \mathrm{~nm}$ respectively. Chlorophyll absorbed red light of 650nm, but did not absorb infrared light of 940nm which was emitted and received to mainly eliminate the influence of leaf thickness on determination results. After reaching leaf, some of red light was absorbed by leaf chlorophyll, and the remaining passed through leaf and was converted into electric signal through receiver. The chlorophyll content in leaf was determined by comparing the intensity of emission light with that of light received by receiver (SPAD unit):

$$
\mathrm{SPAD}=\mathrm{Klg}\left[\frac{I R_{t} / I R_{0}}{R_{t} / R_{0}}\right]
$$

Wherein, K: Constant; IRt: Intensity of received 940nm infrared light; IR0: Intensity of emission infrared light; Rt: Intensity of received $650 \mathrm{~nm}$ red light; and R0: Intensity of emission red light.

\subsection{Data Analysis}

This study analyzed the correlation of several spectral parameters with chlorophyll content and LAI in tobacco canopy. This study selected significantly-related sensitive waveband and spectral parameters, established chlorophyll content and LAI monitoring model through regression analysis, and optimized the equation through estimated standard error (SE) and determination coefficient $\left(\mathrm{R}^{2}\right)$. Spectral parameters were shown in Table 1. 
Table 1. Hyperspectral parameters used in this study

\begin{tabular}{cl}
\hline $\begin{array}{c}\text { Spectral } \\
\text { parameter }\end{array}$ & \multicolumn{1}{c}{ Algorithm formula and definition } \\
\hline RVI & RVI=NIR/RED \\
NDVI & NDVI=(NIR-RED $) /(\mathrm{NIR}+\mathrm{RED})$ \\
NDVIgreen & NDVIgreen=(NIR-Green $) /(\mathrm{NIR}+\mathrm{Green})$ \\
SAVI & SAVI $=1.5 *(\mathrm{NIR}-\mathrm{RED}) /(\mathrm{NIR}+\mathrm{RED}+0.5)$ \\
OSAVI & OSAVI $=(\mathrm{NIR}-\mathrm{RED}) /(\mathrm{NIR}+\mathrm{RED}+0.16)$ \\
MSAVI & MSAVI $=(1 / 2)\left[2 * \mathrm{NIR}+1-\sqrt{(2 * \mathrm{NIR}+1)}{ }^{2}\right.$ \\
& $-8 *(\mathrm{NIR}-\mathrm{RED})]$ \\
MCARI & MCARI $=\left[\left(\mathrm{R}_{700}-\mathrm{R}_{670}\right)-0.2 *\left(\mathrm{R}_{700}-\mathrm{R}_{500}\right)\right]^{*}\left(\mathrm{R}_{700} /{ }_{670}\right)$ \\
\hline
\end{tabular}

\section{Results and Analysis}

\subsection{Raw Spectral Characteristics of Tobacco Canopy}

Tobacco grew slowly, rapidly and then slowly at early, middle and late growth stage respectively. For example, the leaf area and plant height of tobacco increased slowly at $<30,30 \sim 60$ and $>60$ days after the transplantation respectively, i.e. overall like $\mathrm{S}$-shaped growth curve.

At different growth stages, spectral curve of tobacco canopy changed at both same and different tendency, i.e. same at overall tendency but greatly different at local waveband. As shown in Fig.1, at seedling stage, the LAI and chlorophyll content was very small, and the reflectance of visible light $(450 \sim 760 \mathrm{~nm})$ was higher than that ather growth stages due to mulching film. Thus, the canopy reflectance of visible light and near-infrared light was mainly influenced by the content of chlorophyll $\mathrm{a} / \mathrm{b}$, carotenoid and xanthophylls, and the optical characteristics of leaf tissue respectively. With growth progress, there was a continuous increase in tobacco biomass and chlorophyll content, and an increase in LAI. Canopy spectral reflectance decreased to a certain extent within visible light, increased rapidly within near-infrared area, peaked at vigorous growth stage, and gradually decreased at maturity stage with partial leaf harvest.

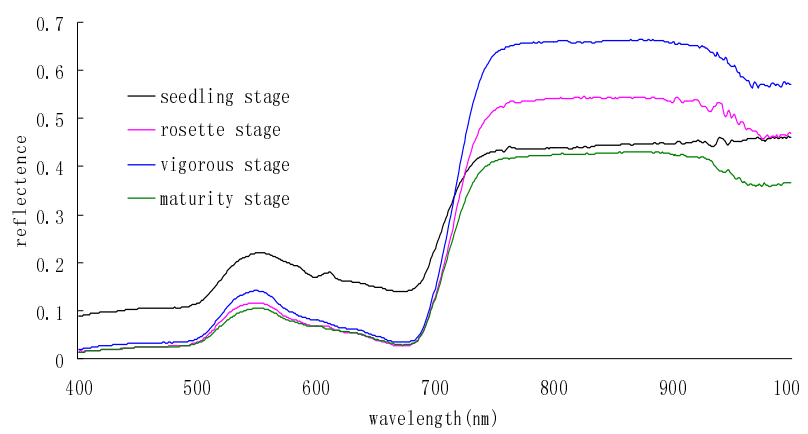

Fig. 1. Canopy spectral characteristic curves of tobacco at different growth stages 


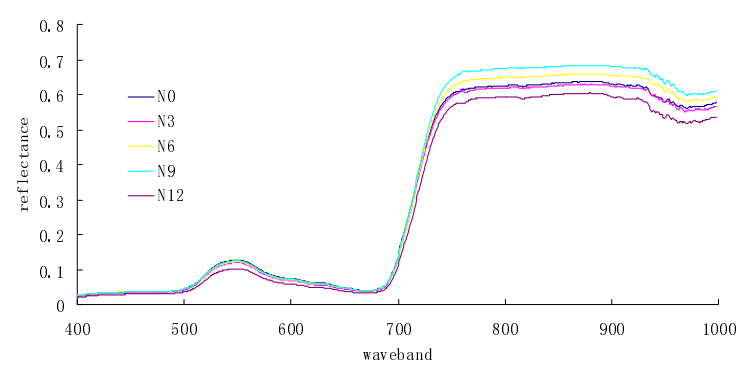

Fig. 2. Canopy spectral characteristic curves of tobacco at different $\mathrm{N}$ levels(Pre-mature stage)

As shown by data at 4 growth stages, the spectral characteristics of tobacco canopy changed roughly at same tendency, but at significant difference for different nitrogen fertilizer levels (and very significantly even at early-maturity stage (Fig.2), i.e. P>0.05 at t test $(760 \mathrm{~nm}, 800 \mathrm{~nm}, 850 \mathrm{~nm}$ and $960 \mathrm{~nm}$ respectively).

\subsection{Correlation of Vegetation Index with Chlorophyll Content and LAI}

As shown by Table 2, LAI was very significantly related to RVI and NDVI (green); and significantly related to NDVI, SAVI and RDVI respectively. NDVI (green) was a spectral parameter closely related to leaf chlorophyll content and LAI.

\subsection{Regression Equation of NDVI (Green) with Chlorophyll Content and LAI}

According to the NDVI (green), regression equation was established for NDVI (green) with LAI. As shown by regression equation with an independent variable of NDVI (green) (Table 3), a regression equation could be established for LAI. Determination coefficient $\left(\mathrm{R}^{2}\right)$ was 0.568 significantly for the regression equation of LAI, and

Table 2. Correlation analyses between vegetable index and chlorophyll, LAI ( $\mathrm{n}=90)$

\begin{tabular}{ccccccccc}
\hline & Item & RVI & NDVI & NDVI(green) & SAVI & OSAVI & MSAVI & RDVI \\
\hline \multirow{3}{*}{ LAI } & Correlation Coefficient & $0.426^{* *}$ & $0.222^{*}$ & $0.484^{* *}$ & $0-.227^{*}$ & -0.062 & -0.125 & $-0.242^{*}$ \\
& Associated Probability & 0 & 0.018 & 0 & 0.08 & 0.575 & 0.147 & 0.023 \\
& Variation Coefficient & 0.546 & 0.003 & 0.007 & -0.004 & 0 & -0.002 & -0.005 \\
\hline
\end{tabular}

Table 3. Regression equations of chlorophyll and LAI by NDVI(green)

\begin{tabular}{cccccr}
\hline Dependent & $\begin{array}{c}\text { Regression } \\
\text { eqution }\end{array}$ & Independent & $\begin{array}{c}\text { The name of } \\
\text { independent }\end{array}$ & $\begin{array}{c}\text { Regression } \\
\text { coefficient Sig }\end{array}$ & R2 \\
\hline LAI & $\mathrm{Y}=0.689+0.035 \mathrm{X} 1$ & $\mathrm{X} 1$ & NDVI(green $)$ & 0.024 & $0.568^{*}$ \\
\hline * Significant $(\mathrm{P}<0.05)$
\end{tabular}

* Significant $(\mathrm{P} \leq 0.05)$ 
regression coefficient was also significant. Thus, the established regression equation was effective, and NDVI (green) could be used to estimate LAI.

\section{Conclusion and Discussion}

Nitrogen is necessary for the growth, development, quality and yield of tobacco. However, excessive nitrogen caused spindly growth, formed black tobacco leaf, and greatly lowered tobacco quality. LAI is important index of tobacco photosynthesis and metabolism, and closely related to final yield and quality. Thus, the fertilization state of field and the growth information of tobacco must be obtained rapidly to support in time the decision on production management. Hyperspectral remote technique is a determination technique to rapidly obtain the growth state of crop.

This study preliminarily described the spectral characteristics of tobacco canopy under different fertilities at different fertilization levels at different growth stages, analyzed the correlation of vegetation index with LAI based on canopy spectrum, and established estimation model. Under different fertilization conditions, the spectral reflectance of tobacco canopy was significantly different, NDVI (green) was significantly related to LAI, and the regression coefficient, association probability and determination coefficient were all significant for established regression. Thus, the screened variable of hyperspectral characteristics was reliable, and relevant model could be used to estimate chlorophyll content and LAI. In the past, many studies were made on wheat,

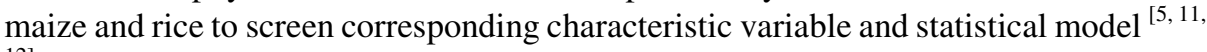
${ }^{12}$. The ratio of near-infrared light to green/red light could significantly improve the sensitivity to parameters of canopy structure. The information of near-infrared light could standardize the established vegetation index, eliminate the influence of canopy structure as far as possible (such as leaf structure, leaf direction and radiation angle), and effectively highlight the information of sensitive waveband (such as green/red light) ${ }^{[13]}$. In this study, the screened NDVI (green) was also based on vegetation index of near-infrared and green lights, and proven also effective for tobacco. In wheat study of Aparicio et.al. ${ }^{[14]}$, the correlation of LAI with vegetation index was not affected by planting measures, species or planting area. But such results on tobacco should be verified through further test.

In this study, SPAD-502 chlorophyll detector was used to rapidly harmlessly determine the chlorophyll content in tobacco. In soybean/maize study of John et.al. ${ }^{[15]}$, the actual amount of chlorophyll extract was very significantly related to the detected data through SPAD chlorophyll detector $\left(\mathrm{R}^{2}=0.94\right)$. Such results appeared in the study of Carlos et.al. ${ }^{[16]}$. In the study of Zeng Jianmin et.al. ${ }^{[17]}$, tobacco chlorophyll was extracted through $95 \%$ water solution of acetone and anhydrous ethanol (2:1 volume); the chlorophyll content in leaf and SPAD value were at very significantly positive correlation; and the chlorophyll content in leaf was estimated through SPAD value to further track the nitrogen nutritional state in tobacco.

In this study, canopy hyperspectral monitored the chlorophyll content and LAI tobacco, rapidly effectively monitored the growth state of tobacco, and provided technological support for tobacco planting and fertilizer management. Of course, the fitting 
equation should be further verified through the tests at different ecosystems and different species, so as to popularize the model and provide theoretic support for large-scale monitoring.

\section{Acknowledgements}

This work was financially supported by the National Key Technology Research and Development Program of China (No. (2006BAD08A01)) and Henan Tobacco Company Projects Grant (HNKJ200814).

\section{References}

1. Shen, G.R., Wang, R.C.: Review of the application of vegetation remote sensing. Journal of Zhejiang University (Agric. \&Life Sci. ) 27(6), 682-690 (2001) (in Chinese)

2. Curran, P.J.: Remote sensing of foliar chemistry. Remote sensing of environment 30, 271-278 (1989)

3. Hinzman, L.D., Bauer, M.E., Daughtry, C.S.T.: Effects of nitrogen fertilization on growth and reflectance characteristics of winter wheat. Remote sensing of environment 19, 47-61 (1986)

4. Svetlana, M.K., Taras, A.K.: Changes in the first derivatives of leaf reflectance spectra of various plants induced by variations of chlorophyll content. Journal of Plant Physiology 12(3), 1648-1655 (2007)

5. Daughtry, C.S.T., Walthall, C.L., Kim, M.S., et al.: Estimating Corn Leaf Chlorophyll Concentration from Leaf and Canopy Reflectance. Remote Sensing of Environment 74(2), 229-239 (2000)

6. Elizabeth, J.B., Brigitte, L., Bernie, Z., et al.: Non-destructive estimation of potato leaf chlorophyll from canopy hyperspectral reflectance using the inverted PROSAIL model. International Journal of Applied Earth Observation and Geoinformation 9(4), 360-374 (2007)

7. Bouman, B.A.M.: Linking physical remote sensing model with crop growth simulation models, applied for sugar beet. International of Remote Sensing 13(2), 2565-2581 (1992)

8. Wu, J.D., Wang, D., Marvin, E.B.: Assessing broadband vegetation indices and QuickBird data in estimating leaf area index of corn and potato canopies. Field Crops Research 102(1), 33-42 (2007)

9. Hung, T.N., Byun, W.L.: Assessment of rice leaf growth and nitrogen status by hyperspectral canopy reflectance and partial least square regress. European Journal of Agronomy 24(4), 349-356 (2006)

10. Liu, G.S.: Tobacco Cultivation, pp. 38-39. China Agriculture Press, Beijing (2003)

11. Feng, W., Yao, X., Zhu, Y., et al.: Monitoring Leaf Nitrogen Concentration by Hyperspectral Remote Sensing in Wheat. Journal of Triticeae Crops 28(5), 851-860 (2008) (in Chinese)

12. Vaesen, K., Gilliams, S., Nackaerts, K.: Ground-measured spectral signatures as indicators of ground cover and leaf area index: the case of paddy rice. Field Crops Research 69(1), $13-25$ (2001)

13. Xue, L.H., Cao, W.X., Luo, W.H., et al.: Relationship Between Spectral Vegetation Indices and LAI In Rice. Acta Phytoecologica Sinica 28(1), 47-52 (2004) (in Chinese) 
14. Aparicio, N., Villegas, D., Araus, J.L., et al.: Relationship between growth traits and spectral veg2etation indices in Durum wheat. Agronomy Journal 42, 1547-1555 (2002)

15. John, M., John, C.O., Jennifer, L.M.: Calibration of the Minolta SPAD-502 leaf chlorophyll meter. Photosynthesis Research 46, 467-472 (1995)

16. Carlos, C., Lianne, M.D., Pierre, D., et al.: Inter-relationships of applied nitrogen, SPAD, and yield of leafy and non-leafy maize genotypes. Journal of Plant Nutrition 24(8), 1173-1194 (2001)

17. Zeng, J.M., Yao, H., Li, T.F., et al.: Chlorophyll Content Determination and its Relationship with SPAD Readings in Flue-cured Tobacco. Molecular Plant Breeding 7(1), 56-62 (2009) (in Chinese) 